\section{Distribuição do maçarico-branco (Calidris alba) entre julho de 2008 e junho de 2009 na praia da Ilha Comprida, São Paulo, Brasil}

\author{
Distribution of Sanderling (Caldris alba), from July 2008 \\ to June 2009 at Ilha Comprida beach, São Paulo, Brazil
}

Roberta Tonolli Chiavone Delchiaro $^{[a]}$, Edison Barbieri ${ }^{[\mathrm{b}]}$ Joaquim Olinto Branco $^{[\mathrm{c}]}$

\section{Resumo}

0 maçarico-branco (Calidris alba) é umas das aves neárticas mais abundantes no Brasil, realiza extensas migrações, se reproduz no hemisfério norte no verão boreal e migra até a Terra do Fogo no inverno boreal. A praia da llha Comprida é um importante local de parada durante a migração da espécie. Por esse motivo 0 objetivo deste trabalho foi analisar a variação mensal e sazonal desta ave na praia da Ilha Comprida. Foram realizados 44 censos ao longo da praia entre o mês de julho de 2008 e junho de 2009. A espécie foi considerada constante entre setembro de 2008 a fevereiro de 2009, sendo que as maiores médias ocorreram no mês de dezembro seguido do mês de outubro, e na estação da primavera. Considerando esses resultados conclui-se que a espécie utiliza a região para repouso e alimentação principalmente na migração para o sul.

Palavras chave: Aves neárticas. Aves de praia. Migração. Variação mensal.

\begin{abstract}
Sanderling (Calidris alba) is one of most abundance neartic bird at Brazil, makes extensive migrations, breads at north hemisphere in boreal summer e migrate to Terra do Fogo in boreal winter. The Ilha Comprida beach is a important stopover during Caldris alba migration. For this reason the aim of this study is analyze a mensal and seasonal variation of this bird at Ilha Comprida beach. The 44 censuses were conducted at beach from July 2008 to June 2009. The species was considered constant from September 2008 and February 2009, the highest averages occurred in December followed by October, and in the spring. The conclusion is that Sanderling uses this area to rest and feed mainly on the south migration.
\end{abstract}

Keywords: Ilha Comprida beach. Migratio. Neartic birds. Shorebird.

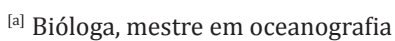
pelo Programa de Pós-Graduação do Instituto Oceanográfico da Universidade de São Paulo (USP), São Paulo, SP - Brasil, e-mail: rupdelchiaro@gmail.com

[b] Oceanógrafo, doutor em oceanografia, pesquisador e professor do Instituto de Pesca APTA- SAASP, Cananéia, SP Brasil, e-mail:

edisonbarbieri@yahoo.com.br

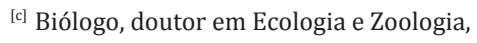
professor da Universidade do Vale do Itajaí (Univali), Itajaí, SC - Brasil: joaquimbranco@univali.br
Recebido: 25/01/2013

Received: 01/25/2013

Aprovado: 23/07/2013

Approved: 07/23/2013 


\section{Introdução}

No Brasil ocorrem sazonalmente 21 espécies das Famílias Charadridae e Scolopacidae (Ordem Charadriiformes) que nidificam na América do Norte durante o verão boreal (Sick, 1997). Migram após procriarem para as áreas de invernada no hemisfério sul. Destas, 17 nidificam exclusivamente nas zonas boreal e ártica e são conhecidas como "aves costeiras neárticas". Charadriidae e Scolopacidae são as famílias que constituem a maioria das aves presentes na zona costeira do Brasil, em termos de número de indivíduos (Vooren \& Brusque, 1999).

Calidris alba pertence à família Scolopacidade, é conhecido popularmente como maçarico-branco, pois apresenta cor branca muito pura, com larga faixa da mesma cor na asa e manto cinza pálido. Alimenta-se principalmente no mesolitoral da praia acompanhando o vaivém das ondas, correndo em velocidade (Hayman, Marchant \& Prater, 1986). É uma das aves neárticas mais abundantes no Brasil e ocorre em todo litoral. Pequenos bandos frequentam até mesmo praias dentro de cidades como o Rio de Janeiro e em certas ocasiões como no Rio Grande do Sul ocorrem em grupos de centenas de indivíduos (Sick, 1997).

Esta ave realiza extensas migrações, podendo migrar do Alasca até a Terra do Fogo na Argentina (Myers, Connors \& Pitelka, 1979). A reprodução ocorre no Ártico entre junho e julho, a partir de agosto os indivíduos começam a migração para os sítios de alimentação (áreas de invernada), onde ficam até meados de abril do ano seguinte. (Lira-Neves, Azevedo-Junior \& Telino-Junior, 2004). Os indivíduos imaturos podem permanecer na área de invernada durante o ano todo (Sick, 1997).

De acordo com Myers et al. (1990) a maioria dos C. alba do novo mundo se reproduz na região de tundra seca no Ártico a $72^{\circ} \mathrm{N}$, principalmente nas ilhas do arquipélago ártico no Canadá, especialmente na Ilha "Prince of wales".

Os pontos de parada ao longo da migração são de extrema importância para as aves que realizam extensas migrações, pois é neles que as aves vão forragear para adquirir energia necessária, afim de seguir a viagem e aumentar as reservas que podem ser essenciais para o sucesso reprodutivo da ave quando chegar ao local de reprodução (Pyke, 1983; Davison \& Evans, 1988; Barbieri, Mendonça \& Xavier, 2000).
Alguns pontos de parada importantes já foram registrados na costa do Brasil, revelando a importância da rota do Atlântico para o maçarico-branco: Barra do Cunhaú, no Rio Grande do Norte (Nascimento \& Larrazábal 2000); Coroa do Avião em Pernambuco (Telino-Junior, Azevedo-Júnior \& Lyra-Neves, 2003, Lyra-Neves et al., 2004), Área de Proteção Ambiental de Piaçabuçu, Alagoas (Cabral, Azevedo-Júnior \& Larrazábal, 2006), praia de Atalaia Nova em Sergipe (Barbieri \& Havennegaard, 2010), Parque Nacional da Lagoa do Peixe, Rio Grande do Sul (Vooren \& Chiaradia, 1990), Praia da Ilha Comprida, em São Paulo ( Barbieri, Mendonça \& Xavier, 2003, Barbieri \& Paes, 2008 ).

Considerando que a praia da Ilha Comprida já foi identificada como local de parada nos anos de 1998 e 1999 por Barbieri et al. (2003) este trabalho teve como objetivo analisar a variação mensal e sazonal de $C$. alba e também estimar a frequência de comportamentos em relação à aproximação das pessoas, nesta mesma região entre julho de 2008 e julho de 2009.

\section{Material e métodos}

\section{Área de estudo}

No extremo sul do Estado de São Paulo ocorre o recuo da escarpa da Serra do Mar, formando a bacia hidrográfica do rio Ribeira de Iguape, cuja foz marca o limite norte do Complexo Estuarino-lagunar de Cananéia-Iguape-Paranaguá, sendo a Ilha Comprida situada na sua região central (Figura 1). Esta ilha possui mais de $70 \mathrm{~km}$ de comprimento, com $3 \mathrm{~km}$ de largura em média, entrecortada por pequenos riachos, sendo assim um grande atrativo para aves e diversos outros animais, que procuram a praia para repouso e alimentação (Barbieri \& Cavalheiro, 1998).

A praia da Ilha Comprida possui extensa faixa arenosa paralela à linha da costa, com sedimentos de granulação fina, homogênea e baixa declividade. As marés astronômicas têm uma altura de aproximadamente 1,80 metros, com uma marcante influência dos ventos no seu nível. A Ilha Comprida é uma ilha de barreira quaternária de sedimentação recente, predominantemente marinha (Suguio \& Martins, 1987), formada pelo acúmulo de materiais arenosos (Tessler, 1988). 


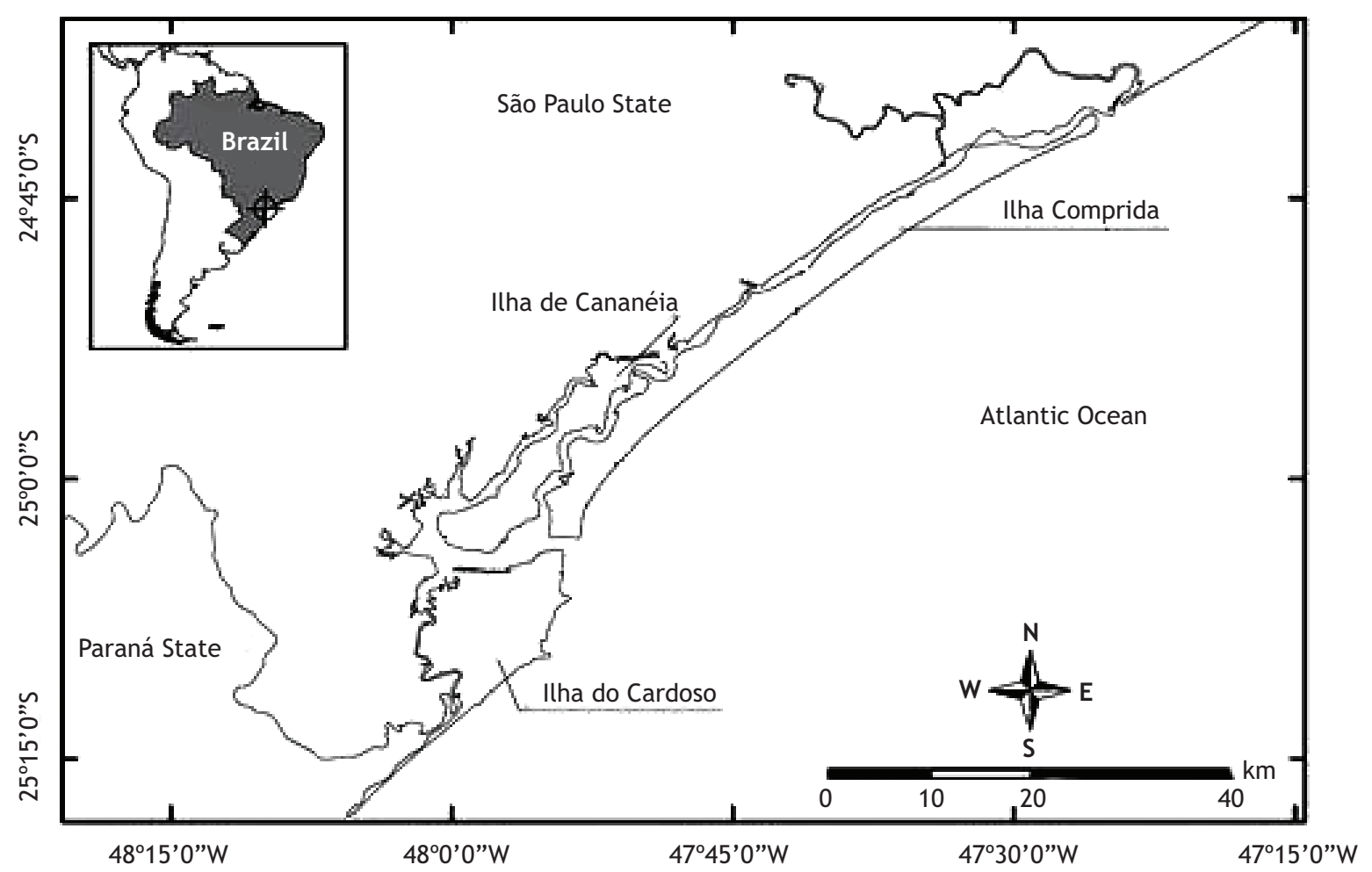

Figura 1 - Localização da Itha Comprida no Complexo Estuarino-Lagunar de Cananéia-Iguape Ilha comprida, São Paulo Fonte: Santos \& Rosso, 2008.

Os censos foram realizados na praia da Ilha Comprida decarrocomvelocidademáximade $40 \mathrm{~km} / \mathrm{h}$ seguindo uma transecção de $72 \mathrm{~km}$ por $200 \mathrm{~m}$ pré-estabelecidos. 0 trajeto percorrido foi sempre iniciado na parte sul da ilha (Boqueirão Sul) trafegando em direção para o norte (Canal de Icarapa). A pesquisa teve duração de 12 meses, entre julho de 2008 e junho de 2009, com amostragens semanais (4 amostras/mês, totalizando 48 saídas). Fez-se saídas em períodos alternados pela manhã (8h$-10 \mathrm{~h})$ e tarde (14h-17h), totalizando 24 amostragens no período da tarde e 24 no período da manhã. Esta metodologia foi sugerida por Bibby, Burges e Hill (1992) para este tipo de ambiente e foi utilizada por Barbieri \& Paes (2008) para censo de aves de janeiro de 1999 a janeiro de 2001 nesta mesma localidade. Os censos tiveram duração de 3 h por amostra, totalizando $144 \mathrm{~h}$ de observação. Para auxiliar na identificação das aves foram utilizados binóculos $(7 \times 50$ e $20 \times 60)$.

As estações do ano foram definidas de acordo com o calendário oficial, ou seja, o verão (21 de dezembro a 20 de março), outono (21 de março a 21 de junho), inverno ( 22 de junho a 22 de setembro) e primavera (23 de setembro a 20 de dezembro).
A Frequência de ocorrência foi calculada por meio da fórmula: (FO): (n/N)*100, sendo $n$ o número de indivíduos encontrado naquele mês e $N$ o número de indivíduos total. Para análise da constância foi utilizada a fórmula $\mathrm{C}:(\mathrm{p} / \mathrm{P})^{*} 100$, sendo $p$ o número saídas a campo em que a espécie ocorreu naquele mês e $P$ o número de saídas a campo no mês (Dajoz, 1973). Em função dos valores obtidos, a espécie foi classificada em constante, quando estava presente em mais de $50 \%$ das visitas, acessória quando presente entre 25 a $50 \%$ das visitas ou, acidentais, quando representaram menos de $25 \%$ das espécies nas visitas. Quando estiverem em 0\%, a espécie foi considerada ausente no mês. Densidade média mensal: $\mathrm{m} / \mathrm{d}$ sendo $m$ a média de indivíduos no mês e $d$ a distância percorrida em quilômetros (72 Km).

A planilha de campo foi baseada em Barbieri et al. (2003) com os seguintes comportamentos: estado de alerta, corrida, voo e indiferentes, com a finalidade de se avaliar quais destes comportamentos eram mais condicionados pela aproximação de pessoas a pé, quando a espécie estava forrageando na praia. As distâncias medidas foram: aproximação entre 0 - $50 \mathrm{~m}$, entre 50 a 100 m, entre 100 a $150 \mathrm{~m}$ e entre 150 a $200 \mathrm{~m}$. Para realizar as mensurações, foi marcado local que a ave 
manifestava o comportamento e a distância da pessoa que estava se aproximando a pé. As medidas foram realizadas com o auxílio de uma trena de $50 \mathrm{~m}$. Os comportamentos em resposta às aproximações das pessoas foram medidos na parte sul da Ilha (Boqueirão Sul).

Para testar as diferenças entre as médias fez-se primeiro o teste de normalidade Shapiro-Wilk. Como as distribuições foram normais utilizou-se o teste estatístico paramétrico ANOVA (Tukey $\mathrm{p}<0,05$ ).

\section{Resultados}

Durante o período de julho de 2008 a junho de 2009 avistou-se 528 indivíduos do maçarico-branco, com aumento da densidade de setembro a dezembro e diminuição a partir de fevereiro com ausência em julho (Tabela 1). Não houve diferença estatística no numero de indivíduos entre o período da manhã e tarde (Figura 2).

Tabela 1 - Número total de indivíduos de Calidris alba avistados no período de julho de 2008 a junho de 2009 , com as respectivas médias, desvio padrão, densidade média e frequência de ocorrência

\begin{tabular}{lccccc}
\hline \multicolumn{1}{c}{ Meses } & $\mathbf{N}^{\circ}$ Total & Média & Desvio Padrão & Densidade Média & Frequência de ocorrência \\
\hline Julho de 2008 & 0,00 & 0 & 0 & 0,00 & 0 \\
Agosto de 2008 & 2 & 0,5 & 0,5 & 0,02 & 50 \\
Setembro de 2008 & 115 & 28,75 & 21,1 & 1,64 & 75 \\
Outubro de 2008 & 88 & 22 & 8,8 & 1,25 & 100 \\
Novembro de 2008 & 82 & 20,5 & 16,6 & 1,17 & 75 \\
Dezembro de 2008 & 272 & 47,5 & 54,4 & 3,88 & 75 \\
Janeiro de 2009 & 105 & 26,25 & 30,3 & 1,5 & 75 \\
Fevereiro de 2009 & 26 & 6,5 & 11,0 & 0,37 & 75 \\
Março de 2009 & 14 & 3,5 & 5,7 & 0,2 & 50 \\
Abril de 2009 & 30 & 7,5 & 11,9 & 0,42 & 50 \\
Maio de 2009 & 4 & 1 & 1,4 & 0,05 & 25 \\
Junho de 2009 & 1 & 0,25 & 0,5 & 0,01 & 25 \\
\hline
\end{tabular}

Fonte: Dados da pesquisa.



Figura 2 - Médias de indivíduos de Calidris alba avistados no período da manhã e tarde na praia da Ilha Comprida de julho de 2008 a junho de 2009

Fonte: Dados da pesquisa.

Nota: As barras correspondem aos respectivos desvios padrões. 
Pelos critérios adotados, a espécie foi considerada constante na praia da Ilha Comprida de setembro de 2008 a fevereiro de 2009 , acessória em agosto de 2008, março e abril de 2009, acidentais em maio e junho e ausente em julho de 2009. Dezembro apresentou a maior média de indivíduos $(47,5 \pm 54,4)$ (Figura 3), e a maior densidade média $(3,88$ indivíduos/ $\mathrm{km})$. Seguido por setembro com média de 28,7 ( $\pm 21,1$ ) indivíduos e densidade 1,64 indivíduos /Km. A soma dos indivíduos registrados no período de setembro a dezembro representou $75,3 \%$ dos indivíduos observados na Ilha Comprida (Tabela 1). Em julho de 2008 nenhum indivíduo foi observado na Ilha Comprida (Figura 3). Nestes meses a constância foi zero e a espécie foi considerada ausente.

O maçarico-branco esteve presente na praia da Ilha Comprida em todas as estações do ano. 0 verão apresentou a maior média de indivíduos da espécie $(26,7 \pm 37,5)$ seguido da primavera com média de 23,7
$( \pm 16,4)$ indivíduos. 0 inverno e outono apresentaram valores médios baixos $4( \pm 8,2)$ e $0,25( \pm 0,20)$ respectivamente (Figura 4). Utilizando-se ANOVA $(\mathrm{p}<0,05)$, constatou-se que houve diferença significativa somente no inverno ao se comparem as médias com outras estações ( $F=2,09 ; \mathrm{df}=2,3 ; \mathrm{p}=0,01)$.

Os indivíduos da espécie $C$. alba responderam aos distúrbios produzidos por turistas voando, correndo ou ficando parados em estado de alerta (movendo a cabeça para cima e para baixo). Em $70 \%(\mathrm{~N}=50)$ dos casos, quando as pessoas se aproximaram a menos de $50 \mathrm{~m}$ do maçarico-branco, eles voavam. Quando as pessoas se aproximavam entre 50 a $100 \mathrm{~m}$ corriam em $45 \%$ dos casos. Já quando as pessoas se aproximavam à distância entre 100 a $150 \mathrm{~m}$ ficavam em estado de alerta em 55\% dos casos. Para a distância entre 150 e 200 m, 50\% dos indivíduos ficaram em estado de alerta e 35\% indiferentes à presença humana (Tabela 2).

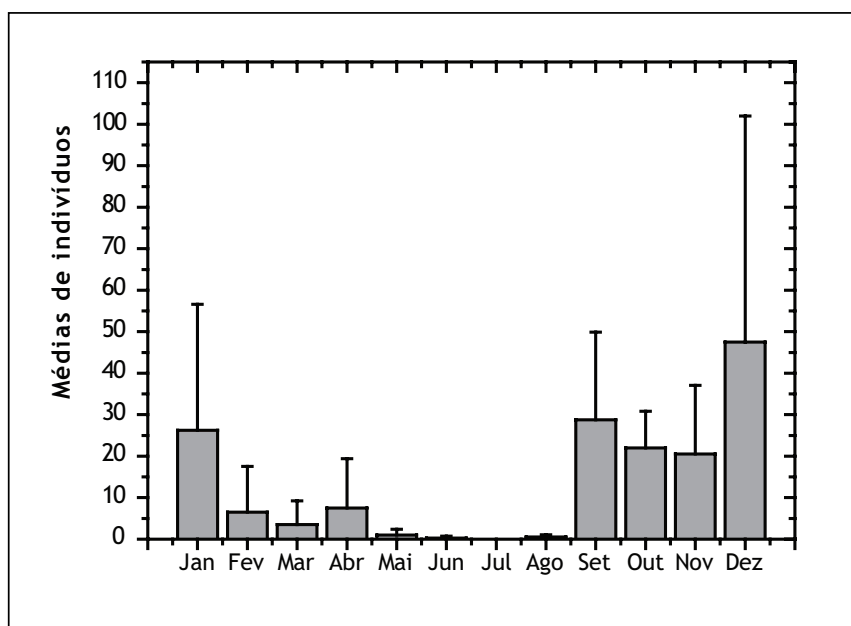

Figura 3 - Médias mensais de Calidris alba avistados ao longo da praia da Itha Comprida entre julho de 2008 e junho de 2009

Fonte: Dados da pesquisa.

Nota: As barras correspondem aos respectivos desvios padrões.

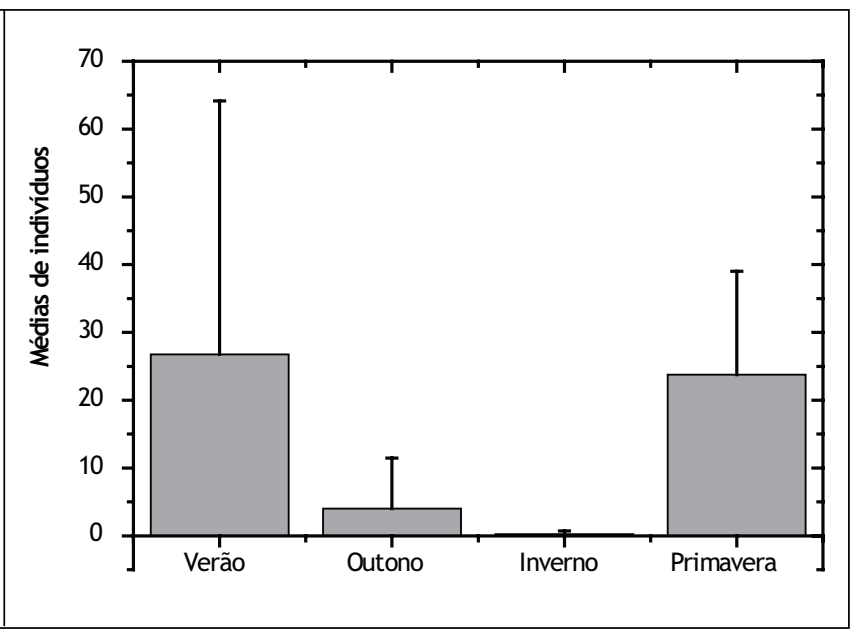

Figura 4 - Variação sazonal de Calidris alba na praia da Ilha Comprida de julho de 2008 a julho de 2009

Tabela 2 - Frequência de comportamentos do C. alba catalogados na praia da Ilha Comprida em relação à aproximação de pessoas $(\mathrm{N}=50)$

\begin{tabular}{ccccc}
\hline & \multicolumn{4}{c}{ Tipos de comportamentos } \\
\cline { 2 - 5 } $\begin{array}{c}\text { Distância } \\
\text { das pessoas }(\mathbf{m})\end{array}$ & Alerta & Corrida & Voo & $70 \%$ \\
\hline $0-50$ & - & $30 \%$ & $20 \%$ & - \\
$50-100$ & $35 \%$ & $45 \%$ & $15 \%$ & $5 \%$ \\
$100-150$ & $55 \%$ & $25 \%$ & $5 \%$ & $35 \%$ \\
$150-200$ & $50 \%$ & $10 \%$ & & Indiferente \\
\hline
\end{tabular}

Fonte: Dados da pesquisa. 


\section{Discussão}

Os resultados deste trabalho revelaram a importância da praia da Ilha Comprida como ponto de parada para a migração de $C$. alba. Foi possível observar a variação mensal e sazonal da espécie, sendo que os picos de ocorrência da espécie foram no mês de dezembro e na estação da primavera entre julho de 2008 e junho de 2009.

Tal pico de ocorrência coincide com a época do ano em que esta espécie está migrando para o sul em busca de locais com alimentação farta e repouso para a muda (Barbieri et al., 2003). A Ilha Comprida parece ser um ponto importante de parada na migração para o sul, porém não foi tão utilizada na migração para o norte no período estudado, pois não há pico significativo no outono. Segundo Sick (1997) as aves neárticas podem escolher rotas diferentes na ida e na volta de forma que uma espécie pode aparecer em um local apenas na vinda ou na volta, além disso, param menos durante a migração para o norte.

Em contrapartida, no trabalho de Vooren e Chiaradia (1990) realizado na praia do Cassino, no Rio Grande do Sul de 1982 a 1986 a espécie foi abundante de fevereiro a abril e ocorreu em pequenos números de abril a dezembro. Segundo esses autores, a ave prefere ambiente lagunar e a praia é utilizada apenas durante a migração para o norte.

A ausência do maçarico-branco nos meses de julho de 2008 e junho de 2009 na Ilha Comprida (Figura 2), pode ser explicado pela maioria dos indivíduos terem migrados para o hemisfério norte para a reprodução. No inverno foram registrados poucos indivíduos na praia da Ilha Comprida. Estes são sub-adultos e jovens ou ainda adultos que não concluíram a muda nas áreas de invernada e não farão a migração para o norte, aguardam próximo período reprodutivo (Telino-Junior et al., 2003). Esse comportamento das aves migratórias também foi registrado por Belton (1984) na praia do Cassino para o maçarico-de-papo-vermelho (Calidris canutus), para a batuíra-de-bando (Charadrius semipalmatus) na praia da Ilha Comprida por Barbieri et al. (2000) e para C. alba por Barbieri e Havenegaard (2008) em Sergipe.

Apesar de Myers et al. (1990) não incluir a rota do Atlântico na migração de $C$. alba, a importância desta foi revelada por meio dos diversos trabalhos realizados na região costeira do Brasil, que foram identificados como pontos de parada para a espécie, como Nascimento e Larrazábal (2000), Barbieri et al. (2003), Lyra-Neves et al. (2004), Cabral et al. (2006), Barbieri e Havenegaard (2008)e Barbieri e Paes (2008).

No estudo de Barbieri et al. (2003), 92\% de C. alba foi observado forrageando na praia da Ilha Comprida e apenas $8 \%$ em descanso, logo essa praia é utilizada principalmente como ponto de parada para alimentação da espécie.

Os locais de alimentação durante a migração funcionam como uma cadeia, se um dos elos da cadeia desaparece as populações que estão chegando ao limite de suas reservas podem ter dificuldades em alcançar o próximo ponto de parada, ou encontrar nova área para se alimentar (Nascimento \& Larrazábal, 2000).

Além disso, o acúmulo de reservas de gordura durante o período de invernada é determinante para o retorno dessas aves para as áreas de reprodução e muitas vezes, a perturbação provocada por atividades humanas pode influenciar em um maior gasto de energia na procura de locais menos impactados (Vooren \& Chiaradia, 1990; Havenegaard \& Barbieri, 2010).

Burger e Gochfeld (1991) afirmam que o aumento de pessoas na praia dificulta a atividade de forrageamento das aves costeiras, pois precisam se mover para sair do caminho dos corredores e veículos e tem que voar quando se sentem ameaçadas. Segundo estes autores conforme o número de pessoas aumentou o tempo que as aves gastam forrageando diminuiu, pois passam mais tempo voando ou correndo dos humanos intrusos o que acarreta em gasto de energia que seria necessária para migração.

A Ilha Comprida apresenta grande potencial para urbanização com fins turísticos, pois possui longa extensão de praia e a ocupação tem ocorrido de forma desordenada (Barbieri \& Pinna, 2005), causando o aumento no número de pessoas e de carros que transitam no mesolitoral onde o C. alba se alimenta, principalmente no verão. A presença humana gera distúrbios para as aves que descansam durante as marés altas, obrigando-as a voarem de um lugar para outro sucessivas vezes, ocasionando, uma perda desnecessária de energia (Burger \& Gochfeld, 1991a; Burger, 1986; Barbieri \& Pinna, 2005). Em resposta ao distúrbio antrópico muitas espécies podem diminuir o tempo de forrageio, pois as aves muitas vezes tendem a voar ou correr quando são perturbadas ou ameaçadas (Burger \& Gochfeld, 1991b; Barbieri et al., 2003; Barbieri, 2007). Quando analisadas as frequências de comportamentos de 
C. alba em relação à aproximação de pessoas, conclui-se que as distâncias menores de 100 m são críticas para a espécie, pois a mesma, invariavelmente, corre ou voa deixando de se alimentar.

Considerando a importância da praia da Ilha Comprida para esta espécie assim como outras aves (Barbieri \& Paes, 2008), existe a necessidade de se tomar medidas para diminuir os impactos antrópicos nesse ambiente. Essas medidas são de grande importância principalmente no verão, que coincide com a época do pico de migração das aves marinhas e também com o aumento de turismo nas praias.

Barbieri e Havenegaard (2010) sugerem algumas estratégias para minimizar o impacto dos turistas sobre as aves costeiras como a instalação de placas educativas desestimulando o turista a se aproximar das aves, criação de áreas de acesso restrito em que há maior abundância de aves, construção das plataformas de observação, de forma que os humanos ficariam concentrados em algumas áreas.

Os resultados deste trabalho revelam a importância da praia da Ilha Comprida como ponto de parada, durante a migração da espécie, por esse motivo necessita urgente de um melhor planejamento urbanístico do município para mitigar efeitos adversos sobre esta e outras espécies de aves.

\section{Agradecimentos}

Ao Instituto de Pesca da Secretaria da agricultura do Estado de São Paulo que possibilitou essa pesquisa e ao CNPq (processo: 308700/2010-4).

\section{Referências}

Barbieri, E., \& Cavalheiro F. (1998) Impacto nos microclimas da Ilha Comprida decorrentes da retirada de vegetação. Boletim Paulista de Geografia, 78, 67-87.

Barbieri, E., Mendonça, J. T., \& Xavier, S. C. (2000). Distribuição da Batuíra-de-bando (Charadrius semipalmatus) ao longo do ano de 1999 na praia da Ilha Comprida. Notas Técnicas da Facimar, 4, 69-76.

Barbieri, E., Mendonça, J. T., \& Xavier, S. C. (2003). Importance of Ilha Comprida (São Paulo State, Brazil) for Sanderlings (Calidris alba) Migration. Journal of Coastal Research, 35, 340-345.
Barbieri, E., \& Pinna, F. V. (2005). Distribuição da batuíra de coleira (Charadrius collaris) durante o período de 1999 a 2001, na praia da Ilha Comprida. Revista Brasileira de Ornitologia, 13, 161-167.

Barbieri, E. (2007). Seasonal abundance of shorebirds at Aracaju, Sergipe, Brazil. Wader Study Group Bulletin, $113,40-46$.

Barbieri, E., \& Havenegaard, G. T. (2008). Seasonal Occurrence and Abundance of Shorebirds at Atalaia Nova Beach in Sergipe State, Brazil. Waterbirds, 31, 636-644.

Barbieri, E., \& Paes, E. T. (2008). The birds at Ilha Comprida beach (São Paulo State, Brazil): a multivariate approach. Biota Neotropica, 9, 41-50.

Belton, W. (1984) Birds of Rio Grande do Sul, Brasil. Part I. Rheidae through Furmariidae. Bull. Armer. Mus. Nat. Hist., 178, 389-636.

Bibby, J. C., Burges, N. D., \& Hill, D. A. (1992). Birds census techniques. London: Academic Press.

Burger, J., \& Gochfeld, M. (1991a). Human activity and influence and diurnal e nocturnal foranging of Sanderlings (Calidris alba). Condor, 93, 259-265.

Burger, J., \& Gochfeld, M. (1991b). Human disturbance and birds: tolerance and response distances of resident and migrant species in India. Enviroment. Conservation. 18,158-165.

Cabral, S. A. S., Azevedo-Júnior, S. M., \& Larrazábal, M. E. (2006). Levantamento das aves da Área de Proteção Ambiental de Piaçabuçu, no litoral de Alagoas, Brasil. Ornithologia, 1,161-167.

Dajoz, R. (1973). Ecologia geral. São Paulo: Editora da Universidade de São Paulo.

Davison, N., \& Evens, P. (1988). Prebreeding acumulation of fat and muscle protein by Artic nesting shorebirds. Proceeding of the International Ornithology Congress. $19,342-352$.

Havenegaard, G. T., \& Barbieri, E. (2010). Shorebirds in state of Sergipe, northeast of Brasil: Pontential Tourism Impact. Revista Brasileira de Ornitologia,18, 169-175.

Hayman, P., Marchant, J., \& Prater, T. (1986). Shorebirds: An identification guide. Boston: Houghton Mifflin Company. 
Lira-Neves, R. M., Azevedo-Junior, S. M., \& Telino-Junior, W. R. (2004). Monitoramento do maçarico-branco, Calidris alba (Pallas) (Aves: Scolopacidae), através de recuperação de anilhas coloridas, na Coroa do Avião. Igarassu, Pernambuco, Brasil. Revista Brasileira de Zoologia, 21, 319-324.

Myers, J. P., Connors, P. G., \& Pitelka, F. A. (1979). Territory size in wintering Sanderlings: the effects of prey abudance and intruder density. The Auk, 96, 551-561.

Myers, J. P., Sallabery, A. M. Ortiz, E., Castro, G., Gordon, L. M., Maron, J. N., et. al. (1990). Migration routes of new world sanderlings (Calidris alba). The Auk, 107, 172-180.

Nascimento, J. L. X., \& Larrazábal, M. E. (2000). Alimentação de aves limícolas em Barra do Cunhaú, Canguaretama, Rio Grande do Norte, Brasil. Melopsittacus 3, 91-109.

Pyke, G.H. (1983). Animal movements: an optimal foraging approch., In I. R. Swingland \& P. J. Greenwood (Ed.). The ecology of animal moviment: (pp. 7-31.) Oxford: Claredon Press.

Santos, M. S. O., \& Rosso, S. (2008). Social Organization of Marine Tucuxi Dolphins, Sotalia guianensis, in the Cananéia Estuary of Southeastern Brazil. Journal of Mammalogy, 89, 347-355.
Sick, H. (1997). Ornitologia Brasileira. Rio de Janeiro: Editora Nova Fronteira.

Suguio, K., \& Martins, L. (1987). Classificação de costas e evolução biológica das planícies litorâneas quaternárias do Sudeste e Sul do Brasil (p 123). Simpósio sobre Ecossistema da Zona Sul e Sudeste Brasileira, Síntese dos conhecimentos. Academia de Ciências do Estado de São Paulo, São Paulo.

Tessler, M. G.(1988). Dinâmica sedimentar quaternária no litoral sul paulista. Tese de doutorado, Instituto de Geologia da Universidade de São Paulo, São Paulo.

Telino-Junior W. R., Azevedo-Júnior' S. M., Lyra-Neves, R. M. (2003). Censo de aves migratórias (Charadriidae, Scolopacidae e Laridae) na Coroa do Avião, Igarassu, Pernambuco, Brasil. Revista Brasileira de Zoologia, 20, 451-456.

Vooren, C. M., \& Brusque, L. F. (1999). As aves do ambiente costeiro do Brasil: Biodiversidade e conservação. Rio Grande: Programa Nacional de Diversidade Biológica.

Vooren, C. M., \& Chiaradia, A. (1990). Seasonal abundance and behavior of coastal birds on Cassino beach, Brazil. Ornitologia neotropical, 1, 9-14. 